\title{
Personality as Relational Resource in Persuasion Settings
}

\author{
Kevin H. C. Cheng (Corresponding author) \\ Department of Sociology and Social Policy \\ Lingnan University \\ Tuen Mun, N.T., \\ Hong Kong
}

Tel: 852-2616 7170

Fax: 852-2891 7940

E-mail: chenghck@LN.edu.hk

\begin{abstract}
The research on which this paper is based was supported by the Direct Research Grant of Lingnan University (Project
\end{abstract} No. DR06B6)

\begin{abstract}
The current study aims to show that, like speech acts, personality is also a social resource, the latter predisposes people to relate to each other in a preferential manner. Fifty-eight participants engaged in dyadic interactions in which they were required to defend their point of view. The translated version of the NEO-FFI was used to measure personality dimensions (McCrae, Costa \& Yik, 1996), and the Verbal Response Mode (Stiles, 1992) was used for the coding of verbal behavior. The results show that people who have a high level of neuroticism handle their interpersonal relationships in a reflective manner by concealing their own opinions and focusing on the arguments of other people. The same people prefer to communicate by "mirroring" other people's utterances, irrespective of the role that was given to them in the study. The findings add to the body of knowledge on interpersonal dimensions and their relations with personality.
\end{abstract}

Keywords: Five Factor Model, Neuroticism, Speech acts, Relational resource, Persuasion

\section{Introduction}

The general finding to emerge in small group research is that verbal behaviors discriminate clearly and quantitatively among roles, relationships, and verbal tasks (Cansler \& Stiles, 1981; Hinkle, Stiles \& Taylor, 1988; McGaughey \& Stiles, 1983; Ng \& Bradac, 1993; Stiles, Putnam, James \& Wolf, 1979; Stiles, Waszak \& Barton, 1979). Despite the weight of this evidence, Stiles (1992) suggested verbal variations within roles (or task or type of relationship) may exist and it is of interest to investigators whom study individual differences in speech usage. The implication is that two people in the same situation choose different ways to express themselves as a reflection of their cognitive process. For instance, the use of words related to insights and causations are indicative of one's change of cognitive activities as well as physical health \& adaptive behaviors (Pennebaker, 1997; Pennebaker, Mayne, \& Francis, 1997). These ideas are not new to personality psychologists because the literature argued that personality traits play an influential role in language usage or verbal behavior (Eysenck, 1986; Furnham, 1990; Goldberg, 1982; Lieberman \& Rosenthal, 2001; Scherer and Giles, 1979). Scherer and Giles (1979) suggested that a subset of extraversion (impulsivity and sociability) and neuroticism (anxiety and obsession) may be related to linguistic and paralinguistic cues. Shavitt, Lowry, and Han (1992) reported that high self-monitors are known to operate on mimicking others' behavior as a way to establish affiliation and rapport (Cheng \& Chartrand, 2003).

When people do not agree in controversial issues, there are individual differences in the way they approach it. Some prefer to assert their point of view while others choose to avoid any form of conflicts at all costs. Infante and Rancer (1982) conceptualized arguementativeness as the extent of an individual to advocate positions on controversial issues and to attack verbally the positions of others. The individual who is more argumentative is predisposed to feel a sense of intellectual excitement and anticipation. They take pleasure in advocating their views against those who disagree with theirs. They seldom avoid the opportunity to argue and perceive every opportunity as a challenge and forms of recreation or amusement. A feeling of accomplishment is often reported when the argument is won. Conceptually, argumentativeness is different from other constructs such as verbal aggressiveness and communication apprehension (McCrosky, 1977). People high on verbal aggressiveness enjoy attacking their interlocutor rather than the issue on hand. They tend to steer away from the topic of the argument or the issue concern and personally derogate the interlocutor. 
The person high in verbal aggressiveness is motivated to demonstrate personal superiority, to establish dominance, or to vent out aggressive strain. Communication apprehension, on the other hand, comes about from actual or anticipatory communication situations which lead to fear or anxiety.

Recently, Mehl, Gosling, \& Pennebaker (2006) used the electronically activated recorder (EAR) and reported consistent behaviors for various Big-five traits. The EAR records 30-seconds segments every 12 minutes during the trackers' living habits in natural settings. The recorded segments represented less than $5 \%$ of the trackers' activities. The results showed that extraverts talked more than introvert and engage in more social interactions. Introverts spent more time alone. Individuals high on the scale of agreeableness are more able to symphonize and swears less. They also used more first person singular pronouns (e.g., I, me, my) to convey personal rapport. Conscientious worked more and spend less in places such as restaurants, bars, or coffee shops. Neurotics argued less and uttered less word than the more emotionally stable. Finally, those open to new experience use more third person pronouns and past tense verbs. They spend more time in restaurants, bars, or coffee shops.

Empirical evidence shows this line of research is promising (Dewaele \& Furnham, 1999, 2000; Gottschalk, 1992; Gottschalk \& Bechtel, 1982; Gottschalk \& Gleser, 1969; Gottschalk, Gleser, \& Hambidge, 1957; Hill, 1996; Isbister \& Nass, 2000; Jung, 1971; Lilley \& Wilkinson, 1983; Nelson \& Groman, 1975; Pennebaker \& King, 1999; Pennebaker \& Lay, 2002; Pincus, Gurtman, \& Ruiz, 1998). The problem, as it has always been, is the identification of particular personality variable with corresponding verbal behavior (particularly the form of behavior).

Leary's (1957) initial work on the interpersonal dimension of personality suggested that people differ from each other in the way they do things to one another. Subsequent developments are better known as the circumplex model (Wiggin, 1997), which organizes interpersonal relations along two orthogonal axes (dominance and nurturance). Interpersonal dimensions, such as ambitiousness, dominance, arrogance, calculation, coldness, being quarrelsome, aloofness, introversion, laziness, submissiveness, unassumingness, ingenuousness, warmth, agreeability, gregariousness, and extroversion differ according to their degree of dominance and nurturance (Wiggin, 1997).

The purpose of the current study is to explore whether individual difference is also reflected in the way people say things to one another. In other words, I question whether people who communicate in a similar way are also very much alike in terms of personality dimensions. In particular, the Five-Factor-Model (aka: Big-5) by Costa and McCrae (1985) will be used instead of the circumplex model. The current study aims to illustrate the extent predispositions influence preferential or strategic ways of persuasion.

There are two apparent benefits when the above purposes are achieved. First, this would contribute to the pile of evidence supporting interdisciplinary researches on the two theories of social behavior. Further, we will be in a stronger position to construe or propose personality as a social resource given that speech act theorists have long advocate speech act as a social resource. Second, we can use the functional aspect of speech acts theory to bridge the gap between personality and verbal behavior, and speculate why people say the things they say. This comes from a stream of researches that discuss the pragmatic nature of verbal behavior. Austin (1975) describes, verbal utterance has the ability to perform and accomplish a motivated goal (e.g., persuasion, manipulation, expression, assertion, command, interrogation). That is, it is not mere descriptions of states of affairs but it serves or drives a purpose.

\subsection{The interactive nature of personality and verbal behavior}

There are also other good grounds to advocate linkage between personality trait and verbal behavior. In psychology, numerous scholars have proposed that personality is a resource, which people use to cope and interact with the social environment (Buss, 1999; Hogan, 1998; MacDonald, 1995; Malloy \& Kenny, 1986; Wilson, Near \& Miller, 1996). Daly (1986) advocated a similar position by stating that individual differences in communication skills and preferences are intertwined. Eysenck (1986) suggested extraversion, neuroticism, and psychoticism "embody the three ways in which people can interact" (p. 137). Empirically, studies have reported the effects of communication apprehension on talkativeness (Daly \& Stafford, 1984); neuroticism and apprehension (Kelly \& Keaten, 2000); and psychoticism and verbal aggressiveness (Heisel, France, \& Beatty, 2003). Other evidence that indirectly supports the interactive nature of personality reported "extraversion" is related to oral communication (Busch, 1982; Carell, Prince \& Astika, 1996; Dewaele \& Furnham, 2000; Ehrman \& Oxford, 1995; Thorne, 1987). This extents to Internet based correspondences where higher levels of extraversion is associated with preference for adjectives, while lower levels of neuroticism is associated with preference for adverbs (Oberlander \& Gill, 2006). Further, people high on the agreeableness dimension accounted for more variability in the extent to which they interact with their readers (Nowson, Oberlander, \& Gill, 2005).

It was found that introverted and extroverted dyads differed across numerous measures of conversational content and style (Thorne, 1987). Introverts and extraverts (measured by the Myers-Briggs Type Indicator) in mixed and matched dyads were subjected to experimental conditions and their conversations analyzed. Thorne found introverts with introverts engaged in focused problem talk, whereas extroverts with extroverts showed a wider range of topics and more 
claims of common ground. Niederhoffer and Pennebaker (2002) reported similar coordination or synchronization of interactions between members of the dyad. They identified this as linguistic style matching which include one person co-varying their use of words with those of the other person. It is also indicative of both conversational engagement and dominance. Pennebaker and King (1999) reported on the association between various linguistic markers and individual differences variables such as need-for-achievement, -affiliation and -power (as measured by the thematic apperception test; Morgan \& Murray, 1935). For instance, need-for-achievement was negatively correlated with immediacy, which included first-person singular (e.g., I, my, me), articles (e.g., a, an, the), and discrepancies (e.g., should, would, could). Need-for-affiliation was negatively correlated with social-past, which included past tense (e.g., walked, were, had) and social (e.g., talk, listen, buddy, group) and making-distinctions, which included exclusive (e.g., but, except, without), tentativity (e.g., maybe, perhaps, guess), negations (e.g., no, never, not), and inclusive (e.g., with, and, include).

Neuroticism, extroversion, openness, agreeableness and conscientiousness (as measured by the five-factor-model; John, Donohue \& Kentle, 1991). Pennebaker and King (1999) suggested the more immediate and simple people's writing, the lower they rate themselves on openness. Neuroticism is positively related to negative emotion words (e.g., nervous, hate, grief) and extroversion positively related to positive emotion words (e.g., pretty, joy, nice, pride) as well as words that refer to others. Dewaele and Furnham (2000) compared linguistic markers between extraverts and introverts in formal and informal setting. Linguistic markers, such as implicit speech style (that is, the use of deictic reference such as pronouns, adverbs, and verbs) and speech rates are both positively and significantly related to extroversion in both formal and informal situations. Lexical richness (or richer vocabulary) and semantic errors (words that were superficially right but that did not fit in the context) are related to introversion only in a formal situation. The prevalence of "err" (a hesitation marker) is high for those who are introvert, but only in a formal situation. In an informal situation, only introverts exhibit longer length utterances.

When subjects were asked to code verbal behaviors in terms of Searles' (1969) speech act categories, their outcome corresponds to various dimensions of interpersonal behaviors (D'Andrade \& Wish, 1985). The results showed the dimensions included cooperative and friendly versus competitive and hostile, dominance versus equality, task oriented and formal versus socioemotional and informal, and intense versus superficial. For reasons discussed in Dewaele and Furnham (2000), scholars in both disciplines are reluctant to extend beyond their domain of interests. And thus psychologists do not elaborate or clarify how interactions take form in verbal exchange. Nor do linguists want (or bother) to explain personal factors attributable to usage difference in verbal behavior across individuals.

\subsection{The Verbal Response Mode (VRM)}

One of the daunting tasks in the assessment of speech style is deciding on the appropriate dimensions of language and the best unit of analysis once the dimensions have been chosen. We need a coding system that is robust across all occasions of social interaction. The subsequent sections will introduce a system that codes conversation utterances in accordance with speech act theory. This study adopts the speech act taxonomy that was devised by Stiles $(1979,1992)$, which is called the verbal response mode (VRM). The VRM "draws on a conceptualization of verbal communication in which people are seen as centers of experience and speech acts are seen as links between them" (1992, p. 66). Stiles utilized eight basic modes that included disclosure (D), edification (E), advisement (A), confirmation (C), question (Q), acknowledgement (K), interpretation (I), and reflection (R). Each of VRM's eight modes describes the relationship between speaking parties. In other words, the types of codes that are recorded during a conversational exchange reflect the nature of the interaction or interpersonal relationship between the interlocutors. According to Stiles (1979), the codes reveal the psychological principles that are exhibited by the interlocutors and also serve to numerically index their relationship.

The disclosure mode of the VRM is a class of utterances that reveal the thoughts, feelings, perceptions, or intentions of the interlocutor. The edification mode comprises utterances that reflect objective information. The advisement mode refers to utterances that are suggestive, demanding, permissive, or prohibitive. Confirmation utterances compare the interlocutor's point of view with that of the recipient. Questions are any form of utterances in which the interlocutor seeks something from the recipient. Acknowledgements convey the reception or acceptance of the utterances of the other. Interpretations are the interlocutor's judgments or evaluations of the other interlocutor's point of view, and reflections refer to utterances in which the interlocutor repeats, reinstates, or reiterates the other interlocutors' experience. Examples of each mode are shown in Table 1.

These eight modes stem from three dichotomous principles: the source of experience, the presumption of experience, and the frame of reference. Each of the principles is oriented by the speaker's or the other's experiences. Utterances that originate from the speaker's experience may be described as informative (INF), for example, when the speaker reveals their own feelings, opinions, or information ("I feel great today," "It's nine o'clock."), whereas those that originate from the experience of the other may be described as attentive, such as when the speaker asks a question or describes the other's feelings ("Where have you been?" "You must be famished"). Disclosure, edification, advisement and confirmation are categories for INF. Utterances that require presumptions about the speaker's experience only may be described as 
unassuming (UNA), whereas utterances that require a presumption about the other's experience may be described as presumptuous. For example, "You acted foolishly" presumes knowledge of the other's volitional behavior; "Make mine medium rare" presumes to guide the other's behavior and in effect seeks to impose an experience on the other: the intention to perform an action; "You probably felt discouraged" presumes to understand the other's feelings; and "We disagree about the morality of euthanasia" presumes to know the other's opinion. In contrast, "I'm sick of spinach," "Fences make good neighbors," and "What does 'laconic' mean?" require presumptions only about the speaker's own experience. Disclosure, edification, question, and acknowledgement are categories for UNA. Finally, utterances that require the speaker to represent the experience from their own personal viewpoint are described as directive (DIR). For example, "I want to go fishing," "Do you want to go fishing?" and "Go fishing" all use the speaker's frame of reference - the experience is understood (or, in the case of the question, is to be understood) from the speaker's viewpoint. In contrast, a more acquiescent utterance such as "You want to go fishing" takes the other's frame of reference and in effect represents the experience as viewed by the other. Disclosure, advisement, question, and interpretation are categories for DIR.

Using these eight modes of speech, the verbal response mode (VRM) codes the illocutionary force of utterances at the pragmatic level. Utterances are coded according to the interlocutor's intent on the occasion of their use (Stiles, 1992), and represent that which the interlocutor wants the other to recognize (Note 1) (Grice, 1957). Hereafter, the pragmatic levels are referred to in abbreviated form as intent $\left(\mathrm{VRM}_{\mathrm{in}}\right)$. In the coding of the utterance "Pick up your clothes", the intentional aspect is advisement $\left(\mathrm{A}_{\mathrm{in}}\right)$. In this case, the utterance has an illocutionary force of an advisement at the pragmatic levels. More subtly, the illocutionary force of "Would you pick up your clothes?" $\left(\mathrm{A}_{\mathrm{in}}\right)$ may appear as a question but it affords an illocutionary force of a request.

The validity of VRM were shown in forensic areas where conversational exchanges signify social status and power relations between courtroom attorney and witness (McGaughey \& Stiles, 1983), professor and student in classroom discussions and laboratory conversations (Stiles, Waszak \& Barton, 1979), and between management and labor representatives in a negotiation session (Hinkle, Stiles \& Taylor, 1988).

(See Table 1 )

The current study is different from the above in that past researches tends to focus in their field specialization. For instance, Dewaele and Furnham (2000) explained the results from a cognitive and biological perspective. Pennebaker and King (1999) addressed the question of whether personality satisfies behavioral consistencies across situations. The studies by Wish, D'Andrade, and Goodnow (1980) and D'Andrade and Wish (1985) identified the correspondence between verbal behavior and interpersonal variables. But the results cannot be taken to support the social (or interactive) aspect of personality. Unlike the study by Wish et al. (1980), the participants in the current study take part in self-report measure of personality and independent evaluators rate their verbal behaviors. This study also provides an opportunity to observe other types of interpersonal dimensions - namely the higher order dimensions of the VRM. Pincus et al., (1998) reported there are dimensions of interpersonal traits (i.e., letting others be free to "do their own thing") that are not accounted for by existing systems of personality (e.g., Five-Factor-Model; refer to below for descriptions). In sum, by examining the overlap between the two theoretical approaches, we can evaluate whether a) people differ in the way they "say" things to each other, and b) there are other dimensions of interpersonal personality - namely, those that conforms to the higher order VRM.

\section{Methods}

\subsection{Participants}

Fifty-eight participants were sampled from students who were enrolled in the introductory psychology course at the University of Hong Kong. There were 24 males and 34 females in the sample, all of whom were aged between 19 and 21, with the exception of two participants who were aged 22 and 25. Other dyadic research has also used a similar sample size (Cappella, 1997; Cappella \& Street, 1989; Mehl, Gosling, \& Pennebaker, 2006; Mehl \& Pennebaker, 2003; Spitzberg \& Cupach, 1985). Gender effects were assessed and it will be reported in subsequent sections.

\subsection{Instruments}

\subsubsection{The Five Factor Model (FFM)}

There is a cross-disciplinary and cross-cultural consensus that the five factor model (Costa \& McCrae, 1985, 1992) is a valid model of personality. The model has proved to be very valuable for researchers outside of the field of personality studies such that it has "matured into a theoretical structure of surprising generality, with stimulating links of psycholinguistics and cross-cultural psychology, cognitive theory, and other areas of psychology" (Digman, 1990: p. 418). The version of the Five Factor Model that is used in this study is a translated version of the NEO-FFI (McCrae, Costa \& Yik, 1996). Past research has established the validity and reliability of the model in the local environment (Hui, Gan, \& Cheng, 2000; McCrae, Yik, Trapnell, Bond \& Paulhus, 1998; Yik \& Bond, 1993). In the model 60 items are used to measure five personality dimensions of neuroticism, extraversion, openness to experience, agreeableness, and conscientiousness. The Cronbach alphas were 0.86 for neuroticism, 0.77 for extraversion, 0.73 for openness to experience, 0.68 for 
agreeableness, and 0.81 for conscientiousness (Costa \& McCrae, 1992).

\subsection{Transcription and Coding of Conversations}

Two undergraduates who had gained experience in coding naturalistic speech through translation courses at the University transcribed the recorded conversations. The combined naturalistic data sets produced 16,995 utterances of all that was said during conversations between the dyad members (Table 2). I and another experienced undergraduate coded the conversations in a two-step process. First, we familiarized ourselves with the conversations by viewing the recorded interactions. We then read the coding manual by Stiles (1992) and continued to refer to it if we had any doubts during the coding procedure. In addition, there were specific indigenous considerations, because an English coding system was adapted for use in a cross-cultural setting (Luke, 1990).

Initially, we used two samples (or two dyads) for practice, each of which produced approximately 300 codes. The practice data were later re-coded, as it was expected that the criteria and system would be incongruous at the beginning, but would become more consistent as the coding reached the end of the batches. We met after we had completed the practice samples to calibrate the coding system. I urged the other coder not to agree unless she had a sound rationale, and told her that she was allowed to have her own subjective views on how the utterances were coded according their understanding of the coding scheme. The inter-rater reliability will be measured using Cohen's Kappa. During this process, we both had copies of the conversations on video, as well as transcriptions. We both previewed the video once before undertaking the coding and continue replaying it while coding the utterances.

An utterance was defined as phrases or sentences that housed one of the VRM intent categories. As is frequently the case, the utterances of persuasion were quite lengthy, and more than one VRM category was used in each speaking turn. These longer utterances could thus be comprised of several VRM categories. Each utterance was coded only for the intentional (or intent) aspect. In the analysis section, it is abbreviated as in (Note 2). In this study, all of the VRM codes are utilized so that there are utterances from interlocutors who advocate for and against the topic. Utterances at the turn-switch are also included. The first two domains are self-explanatory, and "turn-switch" denotes points in the conversation at which interruptions or "turn-taking" took place.

\subsection{Procedures}

Participants in the study took part by indicating their time availability on the notice board for psychological research participation. They did not benefit by earning more credit points, as it is mandatory for students to take part in at least three hours of psychological research to gain exposure to the field of psychological research.

The participants were assigned to a suitable time slot depending on their availability. Upon arrival, they were briefed about the nature of the experimental design. They were given newspaper clippings and Internet-sourced articles on the pros and cons of genetic engineering, which they spent the first hour reading at their leisure. The participants were instructed that they were to discuss the topic in Cantonese (a Chinese dialect) during the second hour for at least 20 minutes. I also warned them that their conversation would be videotaped, and that they were free to leave without risk to their credit points if they did not wish to participate in the study. If there were no objections from the participants, then they signed and dated a consent form. I randomly assigned the participants a role in the discussion. The role of one interlocutor was to advocate the position "genetically modified food should be banned," and the other participant was to advocate the opposite position (Note 3). The participants were then led into separate cubicles so that they could study the reading material on their own, and were allowed to take notes to prepare for the debate.

In the second hour, the dyads were instructed not to look at the video camera that was located either in the top corner of the ceiling or directly in front of them (Note 4). The participants were allowed to bring the reading material and their notes into the video room, but were not allowed to read straight from their notes during the debate. Before the recording started, the participants were instructed to avoid bilingual conversations, and to speak in Cantonese to the best of their ability. Jargon and technical terms, however, did not need to be translated, as this would only inhibit the interlocutors from talking in a smooth and natural way.

In the final section of the study, the students were asked to complete the paper-and-pencil version of the FFM. They were then debriefed on the study aims and allowed to leave the room.

\subsection{Data considerations}

The number of subjects was modest $(\mathrm{N}=58)$, but the number of observations per dyad was quite high. Table 2 reveals the composition of the data for the three sources of utterances - namely those speaking for/ against the debate topic as well as the point when speaking turns. Using Guetzkow's (1950) formula, the unitized reliability for the multiple-coded utterances was 0.07, which Guetzkow pointed out is an acceptable score in the measurement of the disagreement among coders. Using his categorizing reliability formula, the coders that were trained to work with the transcripts achieved a reliability index of 0.75 for the verbal response mode. Cohen's kappa (к) ranged from 0.68 to 0.85 for the eight VRM codes. Kappa values above .80 are generally considered a very good result (Brett, Shapiro, \& Lytle, 1998). We 
attributed some of the unsatisfactory value to the large number of categories.

\section{(See Table 2 )}

Some dyads talked for a longer time than others, and some conversations yielded more codes than others. Past research has dealt with this problem by truncating data at the beginning and sometimes even at the end of the conversation to make every dialogue equal in length. In this study, the codes were transformed into percentages. As a result, the number of utterances for some dyads bears the same percentage portion, and yet they may have a different number of codes. In this way, we are utilizing the verbal response mode (VRM) variables (D, E, A, C, Q, K, I, R and their aggregates) so that they equally reflect the proportion of talk time during each dyadic episode.

The participants in the current study were assigned to their respective partners based on their own time availability. Hence, it is necessary to verify several sources of confinements. First, I assessed whether familiarity (i.e., that is whether the dyads are friends or mere acquaintance) between individuals in dyad would have impacted on the outcomes. In the sample collected, $75 \%$ of dyads were acquaintance and $25 \%$ were friends. The MANOVA revealed no significant difference between personality measures and familiarity. Second, personality scores were not taken into account when assigning individuals to roles. I tested if there are any accidental relations between role and personality scores. The MANOVA revealed that those taking the "should be banned" role scored higher in openness to experience ( $\mathrm{F}=9.15, p$ $=.003$ ) (Note 5). On average, those advocating the "should be banned role" scored higher on openness (mean $=30.24)$ compared to their counterpart (mean $=27.20)$. Other FFM dimensions are not affected with the current convenient group assignment. Third, I tested the relations between role and verbal outcomes. The results showed no evidence that indicate the effect of role on respondents' verbal responses.

Fourth, gender did not interact with the personality dimensions of the FFM. This is true even when the covariance of other dependent variables is accounted for. Fifth, it has been reported that levels of extraversion affect talk time (Gifford $\&$ Hine, 1994). However, the analysis of the data indicated no correlation between number of sentences and FFM and other variables. Percentage of floor did not correlated with extraversion but it did for openness to experience $(\mathrm{r}=.30, p$ $=.03$ ). In addition, I conducted more tests to ensure the results of the analyses are not confined to pre-disposed expectations or hypotheses. One possibility is that there are interactions between several traits and linguistic behavior, for example, if an individual high in both extraversion and neuroticism would display particular behavior. However, when demographic variables are entered as controlled variables, the regression analysis failed to indicate any interactions between traits of the FFM (e.g., neuroticism and extraversion, neuroticism and openness, etc.). Another possibility is to test whether speaker's personality have an effect on the verbal behavior of the recipient. Table-3 revealed no correlations based on this speculation.

(See Table 3)

\section{Results}

Table-4 shows edifications (E) and disclosure (D) (statements of objective and subjective information, respectively) dominated the debate with $31 \%$ and $40 \%$ of the spoken time respectively. These two categories accounted for $71 \%$ of all utterances. This indicates that the bulk of the verbal process was concerned with the exchange of information on objective and subjective issues (D and E), with a secondary emphasis upon agreement and disagreement and attempts to guide or direct behavior (A). This description is consistent with the purpose and content of debates, and with the conceptualizations of other researchers, such as Morley and Stephenson (1977). The VRM coding appears to have (to an extent) quantified the broad outlines of this particular negotiation in a manner that is congruent with theoretical accounts of the negotiation process. Edification $\left(E_{\text {in }}\right)$ is negatively correlated to Question $\left(Q_{\text {in }}\right)(r=-.44, p<.001)$, Acknowledgement $\left(\mathrm{K}_{\mathrm{in}}\right)(\mathrm{r}=-.31, \mathrm{p}<.05)$, and Interpretation $\left(\mathrm{I}_{\mathrm{in}}\right)(\mathrm{r}=-.33, \mathrm{p}<.01)$ at different significant levels. Question $\left(\mathrm{Q}_{\text {in }}\right)$ are positively correlated to Interpretation $\left(\mathrm{I}_{\text {in }}\right)(\mathrm{r}=.33, \mathrm{p}<.01)$ and Reflection $\left(\mathrm{R}_{\text {in }}\right)(\mathrm{r}=.26, \mathrm{p}<.05)$. Interpretation $\left(\mathrm{I}_{\text {in }}\right)$ is also positively correlated to Reflection $\left(\mathrm{R}_{\text {in }}\right)(\mathrm{r}=-.31, \mathrm{p}<.05)$. The correlation table (Table 5) reveals the associations between all of the personality traits are consistent with similar studies (Hui, Gan \& Cheng, 2000; Mount, Barrick, Scullen, \& Rounds, 2005; Wilson, Mendes de Leon, Bienias, Evans, \& Bennett, 2004).

(See Table 4)

(See Table 5)

\subsection{Correspondence between personality of speaker and speech act of speaker}

The correlations between personality and speech act markers are shown in Tables 6. To avoid misleading results due to outliers or extreme scores, we plotted a bivariate scatter-plot to check all of the correlations, which is featured in the following section along with specific details about the relationship between personality traits and speech acts. In general, the results indicate that edification, and acknowledgement are influenced by neuroticism.

\subsection{1 "K - Acknowledgement", "E - Edification,” and Neuroticism}

It can be seen from Table 6 that edification (E) and acknowledgement $(\mathrm{K})$ are highly correlated with neuroticism $(\mathrm{r}=$ 
$-0.42, \mathrm{p}<.001 ; \mathrm{r}=0.29, \mathrm{p}<.05$ for $\mathrm{E}_{\mathrm{in}}$ and $\mathrm{K}_{\mathrm{in}}$ respectively). That is, participants who were nervous during the debate listened more (supportive of acknowledgement response) and informed less (negative correlation with edification). In other words, the participants who had a high level of neuroticism did not use edification-based utterances as a way of persuading their interlocutors even though the circumstances required the exchange of objective information. In the current study, the persuasion exercise requires manipulation and recollection of facts and knowledge. The articulation of facts leads to the coding of edification. The following is an example of a person high in neuroticism when he/she converse with his/her interlocutor. Utterances that were coded as acknowledgement (K) included "yes", "uh-huh", "um", and "er". For edification, the following conversations (in italic bold) are taken from various speakers low in neuroticism.

let me inform you about my position...like Genetically Modified Food it has it's benefits... but why it should be banned, I will look at it this way...like if it is in mass quantity in terms of promotion...in mass production.. I feel problems will emerge... you mentioned it can help those farmers in developing countries .... but I feel, on the contrary, it will help the worthy companies... because they develop the technology and it will not help the farmers ...because it will limit things, like for example it will grow such crops.... crops that are patent by the company ... it will reduce the original crops.... like the rights to use the original, the basic crops .... they will need to go thr these companies ... maybe the profit would be made by the company and not the farmers

but $i$ don' think the problem is... are those businessman going to make a lot of money... actually, this world is not only the problem about $\boldsymbol{G E}$ food... for example, a lot of companies that develop the technology ended up being take over by other companies... or other related companies... it will buy it over, it will make more money from it....this is something I cannot stop.. actually, it cannot be said that... because to prevent this from happening... like making a lot of money.... should we prevent farmers' hard work... so as to ban it.... this is not a reason to ban GE food, I feel this way

but the problem is, it is happening now...and we are doing a lot of research on it... but they haven't gotten it on the market yet...so they are still in the stage of research.... but don't you feel they are exaggerating it... the bad effects that it has... there are no one to bring any news about its bad effect

let's be rationale and ordinal...or instance grapes can be very sour... like all those fruits you are eating... they have been modified for many years...the only difference is that they are using modern technology... so actually they should be more positive...because you will have more control over it...because you can be very accurate...like the genes you want... you can add to it... and those that are unwanted are left out...

because we are in Hong Kong... we are in a developed country...you have money now...you may say...but you know a lot of food even those in China...their production is high...but the farmers are often without much to eat...like eating congee...so why is that so?...because they are poor...they have nothing to eat... all they do is grow... shouldn't they eat as well?... so these countries sell crops to make money... but they end up having nothing not enough to eat... so don't they deserve to eat?... they don't have enough things to eat...the whole population is starving...

(See Table 6)

\subsubsection{VRM role dimensions}

The terms INF, UNA, and DIR, corresponded to the aggregates of the three VRM higher order dimensions of informativeness versus attentiveness, unassumingness versus presumptuousness, and directiveness versus acquiescence, respectively. A positive correlation between INF and a trait indicates that the given trait is positively related to informativeness (likewise for UNA or DIR). Logically, when the correlation is negative, the trait is positively related to attentiveness since it is the polar opposite of informativeness. Table 6 in the above indicates high-N participants prefer to utter remarks with regards to other's experiences $\left(\mathrm{INF}_{\mathrm{in}} ; \mathrm{r}=-0.27, \mathrm{p}<0.05\right.$; alternatively, $\left.\mathrm{ATT}_{\mathrm{in}} ; \mathrm{r}=0.27, \mathrm{p}<0.05\right)$. This includes a composite of modes from VRM's question (Q), acknowledgement (K), interpretation (I), and reflection (R). To account for the simultaneous effects of other variables, a hierarchical regression model was constructed and the results revealed similar findings. That is, when demographic/ descriptive variables (such as role of persuasion (for/ against), familiarity (friend/ acquaintance), age, and gender) and FFM variables (excluding neuroticism) are controlled for, neuroticism positively influences the use of attentiveness-related utterances $\left(\Delta R^{2}=0.1, \Delta F=5.53, \mathrm{df}=1,48, \beta=.35\right.$, $p<0.05$ ). This may indicate that high-N participants avoid asserting their views (or experiences) during social interactions, which have been supported from study by Nelson and Groman (1975). This seems to suggest that those who had a high level of neuroticism were doing nothing more than bringing the experience of their interlocutors out into the open. An alternative and perhaps more parsimonious explanation is that high-N participants were not very expressive, and thus preferred to use speech acts that relates to their interlocutor's experiences. Sample utterances of those who had a high level of neuroticism included "but you were saying that modified food is more nutritious", "is this actually more important than safety", "you forcibly put things into it", and "actually you may solve the problem for those who have nothing to eat". 


\section{Discussion}

The correlation results suggest that people with a high level of neuroticism are predisposed to relate to others in a consistent manner regardless of their interlocutor's personality. In the current setting, they handle their interpersonal relationships in a reflective manner (or focus on the experiences of other people as indicated by the VRM). This "mirroring" method involves questioning, acknowledging, interpreting, or reflecting in an attempt to bring the thoughts and processes of the interlocutor to the surface. They were far from interested in making their interlocutor cognizant of their own thoughts. Consistent with Stiles's (1992) work, perhaps one reason is that being a neurotic, their anxiety at the time of the conversation kept them focus on other's utterances. This is consistent with studies that report an association between neuroticism and communication apprehension (Kelly \& Keaten, 2000). By communicating in this way, people with a high level of neuroticism are not compelled to provide ideas or opinions of their own. Incidentally, this mimicry behavior has also reported to facilitate social interaction and to establish rapport as well as projecting an impression of mannerism (Cheng \& Chartrand, 2003). The advantage of deploying this strategy is that it requires less mental resource (Nelson \& Groman, 1975) and it keeps afloat the conversation. This relational strategy has been shown in previous studies to correspond to the way in which psychoanalysts interact with their patients (Stiles, 1979). Yet, the author is far from claiming psychoanalysis (or psychoanalysts) and neuroticism is causally related.

Another explanation could be related to a behavioral inhibition system (BIS), which Beatty et al., (1998) have used to explain communication apprehension. The BIS, experienced as subjective anxiety, is activated in presence of novel stimuli and perceived threats. It follows that individuals high in neuroticism have an inherited threshold for BIS stimulation so it is more easily activated. Activation of the BIS is also associated with increased attention to negative or threatening situation - such as speaking to strangers. In the current study, this may forced the high-N interlocutor to focus more attention on his/her partner's speech. Again, this was manifested by their verbal behaviors (that is, acknowledgement, question, interpretation and reflection). By the same token, the anxious experience may inhibit current efforts to express one's thoughts or experiences.

The dyadic design of this study shows linguistic behavior (or a category of speech acts) within a given context tends to endure for and tie to a given trait. In particular the notion that personality traits, operationalized by the FFM, are construe as social resources that predispose people to relate to others in various preferential ways, via the use of utterances, seems plausible with the weight of the evidence. The current study also revealed that people are not only different in terms of what they "do" to each other, as Wiggins originally proposed, but people also differ in terms of what they "say" or how they attempt to "relate" to each other. The three VRM dimensions covered major individual differences in social interaction. The current study found that interpersonal behavior exists beyond the orthogonal co-ordinates of dominance and nurturance - a domain that the circumplex model advocates. That is, there are other ways to relate to people other than the circumplex dimension of dominance and nurturance. Instead, interpersonal behaviors - in particular verbal behaviors can be modeled by Stile's VRM dimensions, which in turn are related to how people are systematically differentiated across the population - according to the FFM.

Further, the present study is undertaken using an Asian population. With this in mind one may ask "are there any cultural differences between Hong Kong speaker behavior and those in Europe/US which may have implications to the generalizability of the results?" Based on the results, it seems to support that, while findings in the West found that neurotics express more of their feelings in similar situations, participants in Hong Kong reacted by disclosing less with regards to their personal views.

The results of this study underline two issues in the methodology of psychological research. First, they suggest that behavior in the form of speech acts consistently manifests itself as an attribute of personality traits, although it cannot be stated with confidence that there is a one-to-one correspondence between personality and behavior. Second, the results are encouraging for those who are engaged in dyadic research but who lack the resources to meet the design requirements that are associated with subject assignments, such as the "round-robin" or "block design". This study indicates that dyadic research is possible if one is interested in individual effects.

Base on the results, the correspondence between the theory of personality and the theory of speech acts is promising, given that the two theories arose from completely different disciplines - psychology and linguistics. This further strengthens Austin's (1975) proposition that every single social utterance is an act, rather than merely an utterance that conveys the meaning of the interlocutor. The function of an act is grounded in its ability to perform and accomplish a motivated goal. These acts are intertwined with everyday social interactions, and as a result should also surface in personality traits, as they are utilized during interpersonal interactions. One benefit of examining the extent to which the two theories are interrelated is that the functional aspect of speech acts theory can be used to bridge the gap between personality and behavior, and to discover the reason why the two elements exhibit a causal relationship. We know that behavior differs from one person to the next, but there have been few studies that systematically map verbal behavior with a universal taxonomy of individual differences, especially in the Asian context. This is one future research prospect. 
Over half of the utterances in this study were coded as edifications and disclosures, and the other six speech acts were somewhat under-represented. Although the proportion of coded speech acts was small, concerns about the small sample size were minimized by coding a large number of speech acts. With regards to concerns about the generalizability of the current study, the correspondence between personality variables and speech acts is contextual, and the patterns of correlations in the study are specific to conversations about topics that are formal, debatable, and controversial, and will differ across situations. In interrogative settings, for example, utterances that are related to advisement, interpretation, and reflection may be more abundant, and the production of such utterances calls upon different personality resources, such as agreeableness or disagreeableness.

The interpersonal setting that was used in the study involves an element of debate or competitiveness, as each party had to take an opposing side. Although the data were extracted from a naturalistic setting, in other environments the nature of interaction is much friendlier and more casual. Given that the social setting constrains and governs the speech acts of interlocutors, some of the speech acts in this study, such as disclosure and edification, occurred more frequently than others, such as reflection and interpretation. Because of this, we were unable to review every facet of the VRM and its dependence on a specific personality trait in full. By carrying out a more thorough mapping of the correspondence between personality and speech acts across diverse settings, it might be possible to reveal the habitual interpersonal strategies that a given trait manifests.

\section{Acknowledgements}

I would like to thank the students and staff of the University (especially C. Harry Hui) for their kind assistance. I would also like to thank William B. Stiles for his permission to duplicate information about the VRM from Stiles (1992) in Table 1.

\section{References}

Austin, J. L. (1975). How to do things with words. Oxford: Oxford University Press.

Beatty, M., McCroskey, J. C., \& Heisel, A. D. (1998). Communication apprehension as temperamental expression: a communibiological paradigm. Communication Monographs, 65, 197-219.

Brett, J. M., Shapiro, D. L., \& Lytle, A. L. (1998). Breaking the bonds of reciprocity in negotiations. Academy of Management Journal, 41, 410-24.

Busch, D. (1982). Introversion-extraversion and the EFL proficiency of Japanese students. Language Learning, 32 , 109-132.

Buss, D. M. (1999). Human nature and individual differences: The evolution of human personality. In L. Pervin, (Ed) \& O. P., John, (Ed)., Handbook of personality: theory and research (2nd ed.) (pp. 31-56). New York: Guilford Press.

Cansler, D. C., \& Stiles, W. B. (1981). Relative status and interpersonal presumptuousness. Journal of Experimental Social Psychology, 17, 459-471.

Cappella, J. N. (1997). Behavioral and judged coordination in adult informal social interactions: vocal and kinesic indicators. Journal of Personality and Social Psychology, 72, 119-131.

Cappella, J. N., \& Street, R. L. (1989). Social and linguistic factors influencing adaptation in children's speech. Journal of Psycholinguistic Research, 18, 487-519.

Carell, P., Prince, M., \& Astika, G. (1996). Personality types and language learning in an EFL context. Language learning, 46, 75-99.

Cheng, C. M., \& Chartrand, T. L. (2003). Self-monitoring without awareness: using mimicry as a nonconscious affiliation strategy. Journal of Personality and Social Psychology, 85, 1170-1179.

Costa, P. T., \& McCrae, R. R. (1985). The NEO personality inventory manual. Odessa, FL: Psychological Assessment Resources.

Costa, P. T., \& McCrae, R. R. (1992). Revised NEO personality inventory (NEO PI-R): professional manual. Odessa, FL: Psychological Assessment Resources.

Daly, J. A. (1986). Personality and interpersonal communication: issues and directions. In J. C. McCroskey and John A. Daly, Personality and interpersonal communication (pp. 13-41). Beverly Hills, CA: Sage.

Daly, J. A., \& Stafford, L. (1984). Correlates and consequences of social communicative anxiety. In J. Daly, \& J. McCroskey (eds.), Avoiding communication: shyness, reticence, and communication apprehension (pp. 125-144). Beverly Hills, CA: Sage.

D'Andrade, R. G., \& Wish, M. (1985). Speech act theory in quantitative research on interpersonal behavior. Discourse Processes, 8, 229-259.

Dewaele, J. M., \& Furnham, A. (1999). Extraversion: the unloved variable in applied linguistic research. Language Learning, 49, 509-544. 
Dewaele, J. M., \& Furnham, A. (2000). Personality and speech production: a pilot study of second language learners. Personality and Individual Differences, 28, 355-365.

Digman, J. M. (1990). Personality structure: emergence of the five-factor model. Annual Review of Psychology, 41, 417-440.

Ehrman, M., \& Oxford, R. (1995). Cognition plus: correlates of language learning success. The Modern Language Journal, 79, 67-89.

Eysenck, H. J. (1986). Can personality study ever be scientific? Journal of Social Behavior and Personality, 1, 3-19.

Furnham, A. (1990). Language and personality. In H. Giles \& W. Robinson (eds.), Handbook of Language and Social Psychology (pp.73-95). Wiley, Chichester.

Gifford, R., \& Hine, D. W. (1994). The role of verbal behaviour in the encoding and decoding of interpersonal dispositions. Journal of Research in Personality, 28, 115-132.

Goldberg, L. R. (1982). From ace to zombie: some explorations in the language of personality. In C. D. Spielberger \& J. N. Butcher (eds.), Advances in personality assessment (vol. 1, pp.203-234). Hillsdale, NJ: Lawrence Erlbaum Associates.

Gottschalk, L. A. (1992). New findings and clinical applications in the measurement of psychological dimensions in children and adults through the content analysis of verbal behavior. New York: Guilford Publications.

Gottschalk, L. A., \& Bechtel, R. J. (1982). The measurement of anxiety through the computer analysis of verbal samples. Comprehensive Psychiatry, 23, 364-369.

Gottschalk, L. A., \& Gleser, G. C. (1969). The measurement of psychological states through the content analysis of verbal behavior. Los Angeles, Berkeley: University of California Press.

Gottschalk, L. A., Gleser, G. C., \& Hambidge, G. (1957). Verbal analysis. Some content and form variables in speech relevant to personality adjustment. Archives of Neurology and Psychiatry, 77, 300-311.

Grice, H. P. (1957). Meaning. Philosophical Review, 64, 377-388.

Guetzkow, H. (1950). Unitizing and categorizing problems in coding qualitative data. Journal of Clinical Psychology, 6 , 47-58.

Heisel, A. D., France, B. H., \& Beatty, M. J. (2003). Self-reported extraversion, neuroticism, and psychoticism as predictors of peer rated verbal aggressiveness and affinity-seeking competence. Communication Monograph, 70, 1-15.

Hill, C. A. (1996). Interpersonal and dispositional influences on problem-related interactions .Journal of Research in Personality, 30, 1-22.

Hinkle, S., Stiles, W. B., \& Taylor, L. A. (1988). Verbal processes in a labour/management negotiation. Journal of Language and Social Psychology, 7, 123-136.

Hogan, R (1998). Reinventing personality. Journal of Social and Clinical Psychology, 17, 1-10.

Hui, C. H., Gan, Y., \& Cheng, K. (2000). The Chinese personality at work questionnaire: development, validation, and significance. Acta Psychologica Sinica, 32, 443-452.

Infante, D. A., \& Rancer, A. S. (1982). A conceptualization and measure of argumentativeness. Journal of Personality Assessment, 46, 72-80.

Isbister, K., \& Nass, C. (2000). Consistency of personality in interactive characters: verbal cues, non-verbal cues, and user characteristics. International Journal of Human-Computer Studies, 53, 251-267.

John, O. P., Donohue, E. M., \& Kentle, R. L. (1991). The big five inventory - version $4 a$ and $4 b$ (technical report). Berkley: Institute for personality and social research, University of California.

Jung, C. G. (1971). Psychological Types. Princeton, NJ: Princeton University Press.

Kelly, L., \& Keaten, J. A. (2000). Treating communication anxiety: implications of the communibiological paradigm. Communication Education, 49, 45-57.

Leary, T. (1957). Interpersonal diagnosis of personality: a functional theory and methodology for personality evaluation. NY: Ronald Press.

Lieberman, M. D., \& Rosenthal, R. (2001). Why introverts can't always tell who likes them: multitasking and nonverbal decoding. Journal of Personality and Social Psychology, 80, 294-310.

Lilley, A., \& Wilkinson, W. J. (1983). Personal characteristics of teachers and their oral interaction in further education classrooms. Research in Science \& Technological Education, 1, 53-63.

Luke, K. K. (1990). Utterance particles in Cantonese conversation. Amsterdam: John Benjamins. 
Malloy, T. E., \& Kenny, D. A. (1986). The social relations model: an integrative method for personality research. Journal of Personality, 54, 199-225.

McCrae, R. R., Costa, P. T., \& Yik, M. S. M. (1996). Universal aspects of Chinese personality structure. In M. H. Bond, (Ed). The handbook of Chinese psychology (pp. 189-207). Hong Kong : Oxford University Press.

McCrae, R. R., Yik, M. S. M., Trapnell, P. D., Bond, M. H., \& Paulhus, D. L. (1998). Interpreting personality profiles across cultures: bilingual, acculturation, and peer rating studies of Chinese undergraduates. Journal of Personality and Social Psychology, 74, 1041-1055.

McCroskey, J. C. (1977). Oral communication apprehension: a summary of recent theory and research. Human Communication Research, 4, 78-96.

MacDonald, K. (1995). Evolution, the five-factor model, and levels of personality. Journal of Personality, 63, $525-567$.

McGaughey, K. L., \& Stiles, W. B. (1983). Courtroom interrogation of rape victims: verbal response mode use by attorneys and witness during direct examination vs. cross-examination. Journal of Applied Social Psychology, 13, 78-87.

Mehl, M. R., Gosling, S. D., \& Pennebaker, J. W. (2006). Personality in its natural habitat: manifestations and implicit folk theories of personality in daily life. Journal of Personality and Social Psychology, 90, 862-877.

Mehl, M. R., \& Pennebaker, J. W. (2003). The sounds of social life: a psychometric analysis of students daily social environments and natural conversations. Journal of Personality and Social Psychology, 84, 857-870.

Morgan, C., \& Murray, H. A. (1935). A method for investigating fantasies: the thematic apperception test. Archives of Neurology and Psychiatry, 34, 289-306.

Morley, I. E., \& Stephenson, G. M. (1977). The Social Psychology of Bargaining. London: Allen and Unwin.

Mount, M. K., Barrick, M. R., Scullen, S. M., \& Rounds, J. (2005). Higher-order dimensions of the Big Five personality traits and the Big Six vocational interest types. Personnel Psychology, 58, 447-478.

Nelson, W. M., \& Groman, W. D. (1975). Neuroticism verbalizations: an exploration of a Gestalt therapy assumption. Journal of Clinical Psychology, 31, 732-737.

Ng, S. H., \& Bradac, J. J. (1993). Power in language: verbal communication and social influence. Newbury Park: Sage Publications.

Niederhoffer, K. G., \& Pennebaker, J. W. (2002). Linguistic style matching in social interaction. Journal of Language and Social Psychology, 21, 337-360.

Nowson, S., Oberlander, J. \& Gill, A. J. (2005). Weblogs, genres, and individual differences. Paper presented at Cogsci, Stressa, Italy, July 21-23.

Oberlander, J., \& Gill, A. J. (2006). Language with character: a stratified corpus comparison of individual differences in e-mail communication. Discourse Processes, 42, 239-270.

Pennebaker, J. W. (1997). Writing about emotional experiences as a therapeutic process. Psychological Science, 8, 162-166.

Pennebaker, J. W., \& King, L. A. (1999). Linguistic styles: language use as an individual difference. Journal of Personality and Social Psychology, 77, 1296-1312.

Pennebaker, J. W., \& Lay, T. C. (2002). Language use and personality during crises: analyses of mayor Rudolph Giuliani's press conferences. Journal of Research in Personality, 36, 271-282.

Pennebaker, J. W., Mayne, T., \& Francis, M. (1997). Linguistic predictors of adaptive bereavement. Journal of Personality and Social Psychology, 72, 863-871.

Pincus, A. L., Gurtman, M. B., \& Ruiz, M. A. (1998). Structural analysis of social behavior (SASB): circumplex analyses and structural relations with the interpersonal circle and the five-factor model of personality. Journal of Personality and Social Psychology, 74, 1629-1645.

Scherer, K. R., \& Giles, H. (1979). Social markers in speech. Cambridge: Cambridge University Press.

Searle, J.R. (1969). Speech acts: an essay in the philosophy of language. Cambridge: Cambridge University Press.

Shavitt, S., Lowrey, T. M., \& Han, S. (1992). Attitude functions in advertising: he interactive role of products and self-monitoring. Journal of Consumer Psychology, 1, 337-364.

Spitzberg, B. H., \& Cupach, W. R. (1985). Conversational skill and locus of perception. Journal of Psychopathology and Behavioral Assessment, 7, 207-220.

Stiles, W. B. (1979). Verbal response modes and psychotherapeutic technique. Psychiatry, 42, 49-62.

Stiles, W. B. (1992). Describing talk: a taxonomy of verbal response modes. Sage Publications. 
Stiles, W. B., Putnam, S. M., James, S. A., \& Wolf, M. H. (1979). Dimensions of patient and physician roles in medical screening interviews. Social Science \& Medicine, 13, 335-341.

Stiles, W.B., Waszak, C. S., \& Barton,L.R. (1979). Professorial presumptuousness verbal interactions with university students. Journal of Experimental Social Psychology, 15, 158-169.

Thorne, A. (1987). The press of personality: A study of conversations between introverts and extraverts. Journal of Personality and Social Psychology, 53, 718-726.

Wiggins, J. S. (1997). In defense of traits. In R. Hogan, J. Johnson, \& S. Briggs, Handbook of Personality Psychology (pp. 97-117). San Diego: Academic Press.

Wilson, R. S., Mendes de Leon, C. F., Bienias, J. L., Evans, D. A., \& Bennett, D. A. (2004). Personality and mortality in old age. Journal of Gerontology: Psychological Sciences, 59, 110-116.

Wilson, D. S., Near, D., \& Miller, R. R. (1996). Machiavellianism: a synthesis of the evolutionary and psychological literatures. Psychological Bulletin, 119, 285-299.

Wish, M., D'Andrade, R. G., \& Goodnow, J. E. (1980). Dimensions of interpersonal communication correspondences between structures for speech acts and bipolar scales. Journal of Personality and Social Psychology, 39, 848-860.

Yik, M. S., \& Bond, M. H. (1993). Exploring the dimensions of Chinese person perception with indigenous and imported constructs: creating a culturally balanced scale. International Journal of Psychology, 28, 75-95.

Notes

Note 1. Utterances with hidden intent are not coded at this level.

Note 2. Note that RIN refers to an utterance the intention of which is to reflect on what the speaking partner has said.

Note 3. Throughout this paper, interlocutor refers to both speakers, because they are opposing their interlocutor's arguments.

Note 4. This depended on the room in use. Two rooms were used, one of which was a well-equipped video room that is used for video recording using VHS tapes by the Department of Psychology. In the other room, a digital camera with a portable stand was used.

Note 5. Box's Test of Equality of Covariance: $\mathrm{F}=1.16, \mathrm{p}=.30$; Pillai's Trace: $\mathrm{F}=2.62, \mathrm{p}=.03$; Levene's test of equality of error variance: $\mathrm{F}=.001, \mathrm{p}=.973$

Table 1. The Taxonomy of Verbal Response Modes (VRM)

\begin{tabular}{|c|c|c|c|c|}
\hline $\begin{array}{l}\text { Source of } \\
\text { experience }\end{array}$ & $\begin{array}{l}\text { Presumption } \\
\text { about } \\
\text { experience }\end{array}$ & $\begin{array}{l}\text { Frame of } \\
\text { reference }\end{array}$ & $\begin{array}{l}\text { Verbal Response } \\
\text { Mode (VRM) }\end{array}$ & Example \\
\hline \multirow[t]{4}{*}{ Speaker } & Speaker & Speaker & Disclosure & $\begin{array}{l}\text { "I'm finding it hard to listen } \\
\text { today"; "I'm glad you told me } \\
\text { that" }\end{array}$ \\
\hline & & Other & Edification & $\begin{array}{l}\text { "This morning a flying saucer } \\
\text { from Mars landed in New Jersey" }\end{array}$ \\
\hline & Other & Speaker & Advisement & "Tell me about your job" \\
\hline & & Other & Confirmation & $\begin{array}{l}\text { "We agree that the plan is sound"; } \\
\text { "We don't seem to know each } \\
\text { other very well" }\end{array}$ \\
\hline \multirow[t]{4}{*}{ Other } & Speaker & Speaker & Question & $\begin{array}{l}\text { "Have you ever dreamt you were } \\
\text { falling?" }\end{array}$ \\
\hline & & Other & Acknowledgement & "Mm-hm"; "Well, ..." \\
\hline & Other & Speaker & Interpretation & $\begin{array}{l}\text { "You are exaggerating it's } \\
\text { importance" }\end{array}$ \\
\hline & & Other & Reflection & $\begin{array}{l}\text { "You were frightened by his } \\
\text { threats" }\end{array}$ \\
\hline
\end{tabular}


Table 2. Descriptive on interlocutors' discourse

Source of utterance

\begin{tabular}{ll}
\hline For & 7431 \\
Against & 6127 \\
Turn Take & 3437 \\
& \\
Total & 16695
\end{tabular}

For/ Against - participants speaking for (or against) the use of genetic engineering in food

Table 3. Correlation between speaker's personality and recipient's verbal response mode

\begin{tabular}{llllll}
\hline & $\mathrm{N}$ & $\mathrm{E}$ & $\mathrm{O}$ & $\mathrm{A}$ & $\mathrm{C}$ \\
\hline $\mathrm{D}$ & -0.15 & 0.16 & 0.05 & 0.25 & 0.21 \\
$\mathrm{E}$ & -0.11 & -0.01 & -0.10 & -0.04 & 0.00 \\
$\mathrm{~A}$ & -0.22 & -0.05 & 0.26 & 0.07 & 0.25 \\
$\mathrm{C}$ & 0.17 & -0.12 & -0.03 & -0.15 & 0.04 \\
$\mathrm{Q}$ & -0.04 & 0.03 & 0.07 & -0.01 & -0.16 \\
K & 0.12 & -0.10 & 0.06 & -0.10 & -0.02 \\
I & 0.10 & 0.20 & 0.02 & 0.09 & -0.03 \\
R & -0.05 & -0.07 & -0.10 & 0.10 & -0.06 \\
INF_in & -0.07 & 0.03 & 0.00 & 0.05 & 0.23 \\
UNA_in & -0.11 & 0.10 & -0.01 & 0.09 & 0.05 \\
DIR_in & -0.12 & 0.18 & 0.16 & 0.23 & 0.14 \\
\hline
\end{tabular}

$\mathrm{N}=58$; Diagonals denote means and standard deviations (in bracket)

$* \mathrm{p}<0.05$ (2-tailed)

$* * \mathrm{p}<0.01$ (2-tailed)

$* * * \mathrm{p}<0.001$ (2-tailed) 


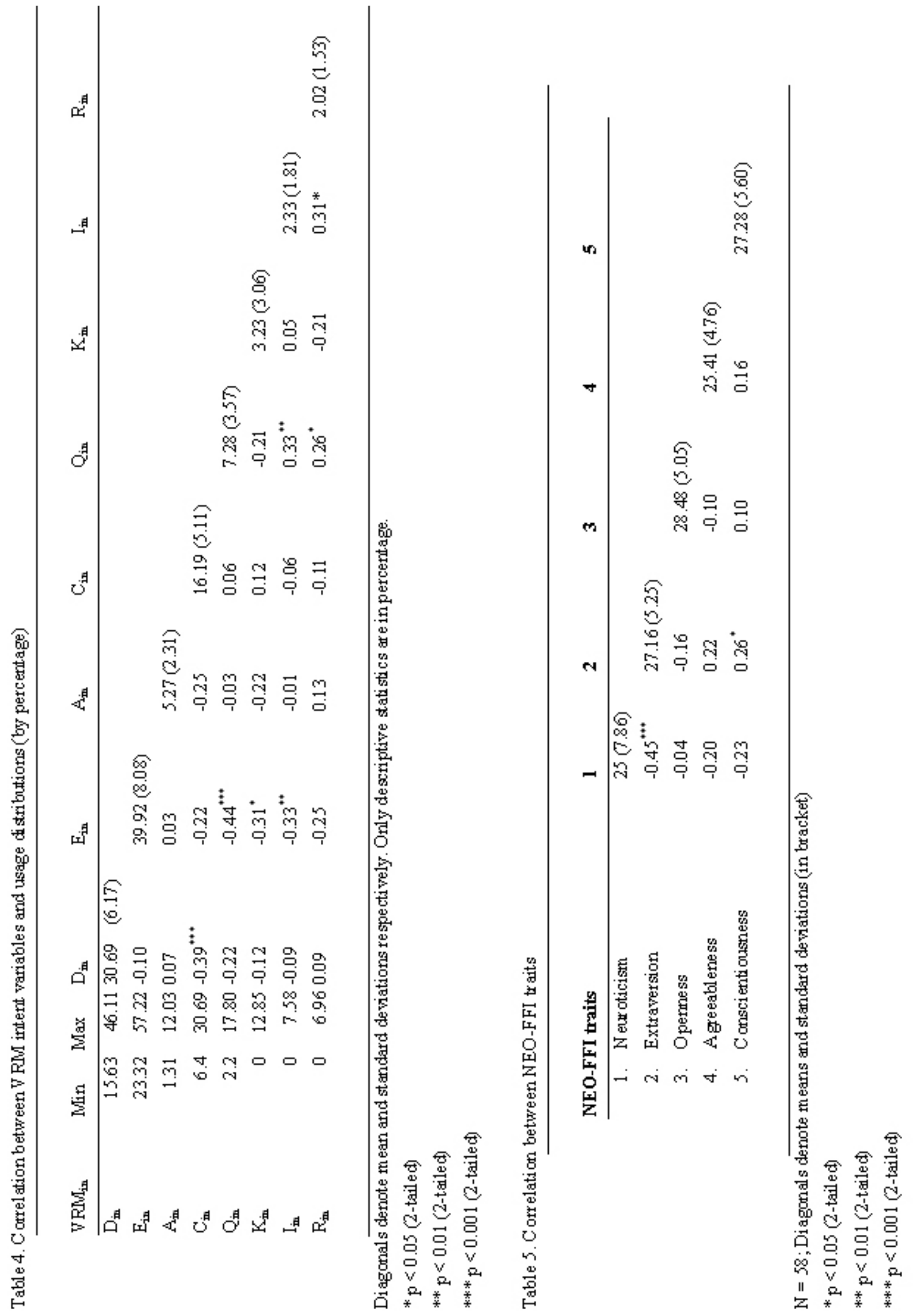


Table 6. Correlation between VRM and Personality (NEO-FFI) of the speaker

\begin{tabular}{lccccc} 
& $\mathbf{N}$ & $\mathbf{E}$ & $\mathbf{O}$ & $\mathbf{A}$ & $\mathbf{C}$ \\
\hline $\mathrm{D}_{\text {in }}$ & -0.07 & 0.09 & -0.22 & 0.07 & -0.07 \\
$\mathrm{E}_{\text {in }}$ & $-0.42^{* * *}$ & 0.01 & 0.05 & 0.16 & 0.24 \\
$\mathrm{~A}_{\text {in }}$ & -0.01 & 0.18 & 0.20 & 0.12 & 0.19 \\
$\mathrm{C}_{\text {in }}$ & 0.08 & -0.17 & 0.15 & -0.03 & 0.11 \\
$\mathrm{Q}_{\text {in }}$ & 0.08 & 0.15 & 0.05 & -0.06 & -0.21 \\
$\mathrm{~K}_{\text {in }}$ & $0.29^{*}$ & -0.25 & -0.12 & -0.16 & -0.12 \\
$\mathrm{I}_{\text {in }}$ & 0.02 & 0.08 & 0.07 & 0.04 & -0.05 \\
$\mathrm{R}_{\text {in }}$ & 0.21 & -0.02 & 0.16 & -0.03 & -0.06 \\
& & & & & \\
$\mathrm{INF}_{\text {in }}$ & $-0.27^{*}$ & -0.04 & -0.01 & 0.13 & -0.24 \\
$\mathrm{UNA}_{\text {in }}$ & -0.22 & 0.00 & -0.20 & 0.09 & -0.15 \\
$\mathrm{DIR}_{\text {in }}$ & 0.05 & 0.19 & -0.10 & 0.07 & \\
& & & & & \\
\hline
\end{tabular}

$\mathrm{N}=58$ (coefficients greater than .26 are significant); 'in' denote intent aspects of the VRM

$\mathrm{N}$ - Neuroticism; E - Extraversion, O - Openness; A - Agreeableness; C - Conscientiousness;

D - Disclosure; E - Edification; A - Advisement; C - Confirmation; Q - Question; K - Acknowledge; I - Interpretation;

$\mathrm{R}$ - Reflection; INF - Informative; UNA - Assumingness; DIR - Directiveness

$* \mathrm{p}<0.05$ (2-tailed)

$* * \mathrm{p}<0.01$ (2-tailed)

$* * * \mathrm{p}<0.001$ (2-tailed) 